Proc. 15th Int. Conference on Defects Recognition, Imaging and Physics in Semiconductors, Warsaw, Poland 2013

\title{
Mapping of Copper Oxidation State Using High Pressure X-Ray Photoelectron Spectroscopy
}

\author{
J. KOWALSKA ${ }^{a, *}$ AND C.S. GOPINATH ${ }^{b}$ \\ ${ }^{a}$ PREVAC sp. z o.o., Raciborska 61, 44-362 Rogów, Poland \\ ${ }^{b}$ Catalysis Division and Center of Excellence on Surface Science, CSIR-National Chemical Laboratory \\ Pune 411 008, India
}

\begin{abstract}
The interaction of $\mathrm{O}_{2}$ with polycrystalline foil of $\mathrm{Cu}$, from ultra high vacuum to 1 mbar and up to $773 \mathrm{~K}$ has been investigated. The study were performed by using the high pressure X-ray photoelectron spectroscopy (electron spectroscopy for chemical analysis) ultraviolet photoelectron spectroscopy system. In this work the results of mapping copper oxidation states as a function of temperature at 1 mbar $\mathrm{O}_{2}$ have been presented.
\end{abstract}

DOI: $10.12693 /$ APhysPolA.125.1065

PACS: 07.05.Tp, 85.60.Gz, 73.40.-c, 78.66.-w

\section{Introduction}

X-ray photoelectron spectroscopy (XPS), also known as electron spectroscopy for chemical analysis (ESCA) is a widely used technique to investigate the chemical composition of surfaces. XPS is routinely used to analyze inorganic compounds, metal alloys, semiconductors, polymers, elements, catalysts, glasses, ceramics, medical implants, bio-materials, viscous oils, glues, ion modified materials and many others. From XPS measurements we can obtain information about identification of elements near the surface, local chemical environments, valence band electronic structure, morphology of thin layers and oxidation states of transition metals. Generally, the identity of the element and the orbital electron binding energies depend both on the local chemical environmental and the formal oxidation state of the atom. An increase in oxidation state causes the binding energy to increase due to a decrease in the screening of the bound electron from the ion core. The ability of XPS to determine oxidation states is used extensively in many research works.

In this article we would like to present the results of mapping copper oxidation states as a function of temperature at $1 \mathrm{mbar} \mathrm{O}_{2}$. For these study the high pressure XPS (ESCA)/ ultraviolet photoelectron spectroscopy (UPS) system was used.

In particular, the XPS (ESCA)/UPS system is dedicated for ambient pressure $1-10^{-10}$ mbar (Fig. 1) photoelectron spectroscopy experiments with controllable sample temperature from $100 \mathrm{~K}$ to $850 \mathrm{~K}$ in analysis chamber. The high precision and repeatability of the chemical analysis are guaranteed by using both the full PLC (Programmable Logic Controller) protection as the software control.

Especially, the software (Fig. 2) provides control of the system, visualisation of machine state, date acquisition and possibility to control other devices connected to the

*corresponding author; e-mail: j.kowalska@prevac.pl

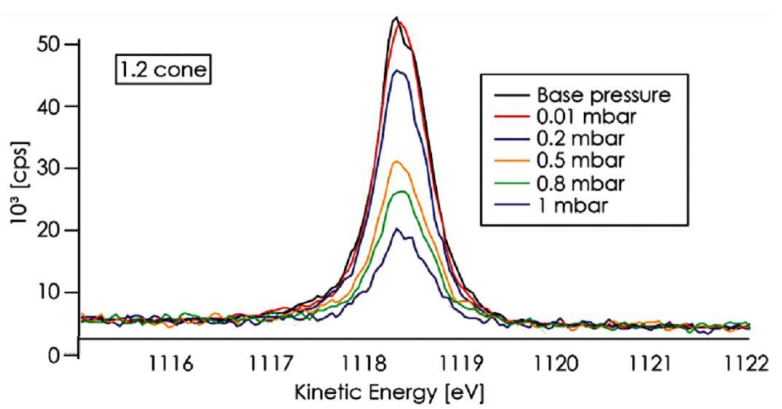

Fig. 1. Ag $3 d_{5 / 2}$ XPS recorded under different pressure of $\mathrm{N}_{2}$.

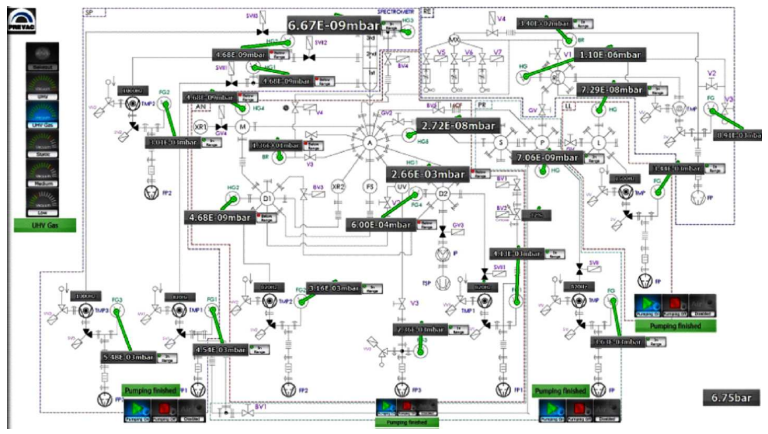

Fig. 2. The scheme of software in XPS (ESCA)/UPS system.

system like UV power supply, etc. The XPS (ESCA)/ UPS system is equipped with VG Scienta R3000 HP analyser and three differentially pumped components: the $\mathrm{X}$-ray monochromator, the double anode X-ray source and the UV source. The high vacuum quality is ensured by the four pumping stages for main chamber and analyser. The unique laser heating method using the laser and resistive heating of sample holder, allows to make analysis in a wide temperature range 100-2200 K.

The XPS (ESCA)/UPS system is equipped with a high pressure reactor (up to $p=20$ bar and $T=650{ }^{\circ} \mathrm{C}$ ) and gas dosing system with ability of heating and thermal sta- 


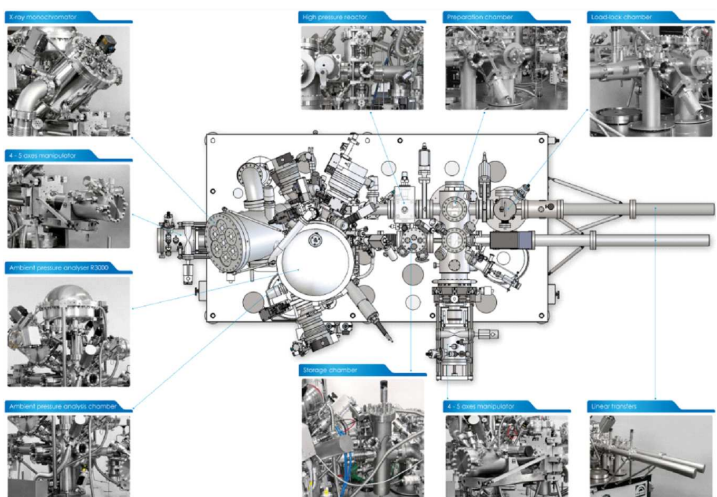

Fig. 3. The scheme of XPS (ESCA)/UPS system.

bilisation. The special sample preparation chamber with 5 sample holders makes this system easy, friendly and economic to operate. Additionally, thanks to the special heating and temperature control systems, the thermal desorption spectroscopy (TDS) measurements can be successfully realised. Simultaneous XPS and reaction kinetic measurements on solid surfaces make this system an important tool to measure the dynamic electronic structure changes on material surfaces under reaction conditions. The complete scheme of the XPS (ESCA)/UPS system with the main components is presented in Fig. 3 . This system was designed and completely made by PREVAC.

\section{Results}

The $\mathrm{Cu} 2 p, \mathrm{Cu} L M M$ Auger level and valence band (VB) spectra recorded in the presence 1 mbar $\mathrm{O}_{2}$ from room temperature (RT) to $675 \mathrm{~K}$ are shown in Figs. 4-6 [1]. The $\mathrm{Cu} 2 p$ spectrum from a clean $\mathrm{Cu}$

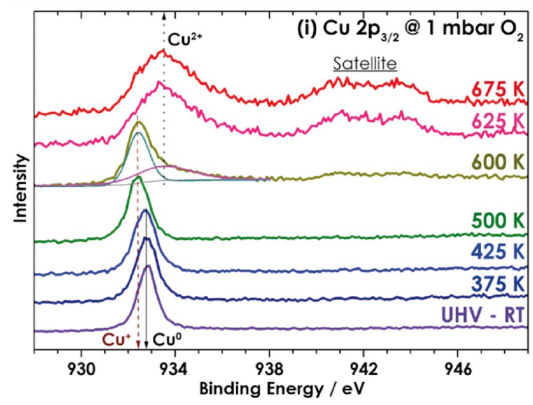

Fig. 4. XPS Cu $2 p$ core level spectra measured while exposing a polycrystalline $\mathrm{Cu}$ foil to $1 \mathrm{mbar}_{2}$ at various temperatures.

surface obtained under UHV conditions and at RT immediately after $\mathrm{Ar}^{+}$sputtering and annealing is shown for reference (bottom-most trace in all figures). The $\mathrm{Cu}$ $2 p_{3 / 2}$ core level spectrum centred at $932.8 \mathrm{eV}$ (grey solid arrow) which is characteristic of metallic $\mathrm{Cu}$ remains unchanged until $425 \mathrm{~K}$ indicating that the metallic nature of $\mathrm{Cu}$ surface is retained until this temperature. $\mathrm{Cu} L M M$ also shows corresponding feature at $918.8 \mathrm{eV}$.

On increasing the temperature to $500 \mathrm{~K}$, a dramatic change in oxidation state to $\mathrm{Cu}^{+}$(i.e. $\mathrm{Cu}_{2} \mathrm{O}$ ) is evident

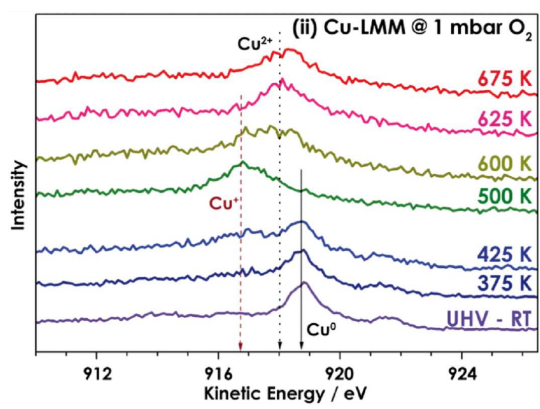

Fig. 5. XPS $\mathrm{Cu} L M M$ core level spectra measured while exposing a polycrystalline $\mathrm{Cu}$ foil to $1 \mathrm{mbar} \mathrm{O}_{2}$ at various temperatures.

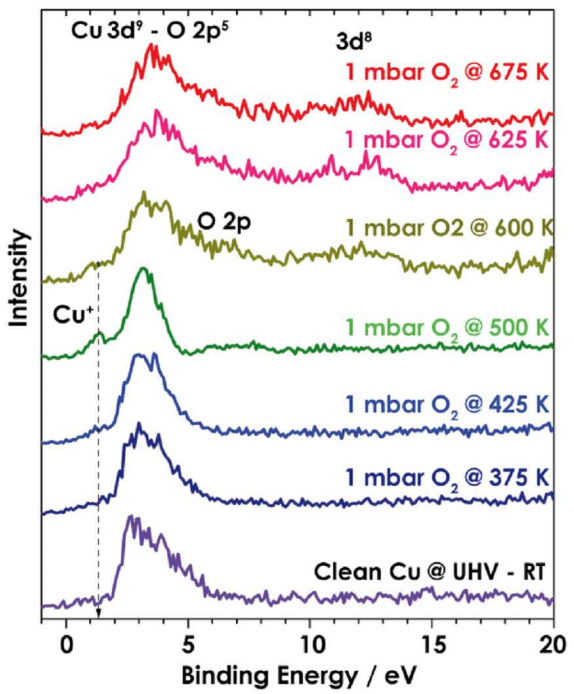

Fig. 6. High pressure valence band spectra recorded at 1 mbar $\mathrm{O}_{2}$ and at different temperatures. Systematic conversion of $\mathrm{Cu}$ metal at UHV RT to $\mathrm{Cu}_{2} \mathrm{O}$ (at $500 \mathrm{~K}$ ) and $\mathrm{CuO}$ above $500 \mathrm{~K}$ is observed in 1 mbar $\mathrm{O}_{2}$.

from the shift observed in $\mathrm{Cu} 2 p$ (to $932.4 \mathrm{eV}$ ), $\mathrm{Cu} L M M$ (to $916.7 \mathrm{eV}$ ) compared to metallic $\mathrm{Cu}$ features. A distinct feature appears at $1.2 \mathrm{eV}$ with a narrowing of $\mathrm{VB}$ feature.

Further increase in temperature to $600 \mathrm{~K}$ shows features due to $\mathrm{Cu}_{2} \mathrm{O}$ as well as $\mathrm{CuO}$. This marks the beginning of oxidation of $\mathrm{Cu}_{2} \mathrm{O}$ to $\mathrm{CuO}$. A prominent satellite feature, typical for $\mathrm{CuO}\left(\mathrm{Cu}^{2+}\right.$ oxidation state), begins to appear along with a shift in $\mathrm{Cu} L M M$ feature. Broadening of VB with $\mathrm{O} 2 p$ features confirms the oxidation of $\mathrm{Cu}_{2} \mathrm{O}$ to $\mathrm{CuO}$. Spectra recorded at 625 and $675 \mathrm{~K}$ fully support the complete oxidation of $\mathrm{Cu}$ surfaces to $\mathrm{CuO}$, and sufficiently thick $\mathrm{CuO}$ layers observed suggest the beginning of bulk oxidation towards $\mathrm{CuO}$. Features typical for $\mathrm{CuO}$ were observed in all three spectra, such as $3 d^{8}$ satellites in $\mathrm{Cu} 2 p$ core level.

\section{References}

[1] Kanak Roy, C.P. Vinod, Chinnakonda S. Gopinath, J. Phys. Chem. C 117, 4717 (2013). 